\title{
Pursuit for the Tao through the Silkworm: A Conversation with Liang Shaoji
}

\author{
Yang Jingii
}

\begin{abstract}
The Chinese artist Liang Shaoji has been working intensively with silkworms for almost 30 years. His abundant art practices under the Nature Series have become a unique phenomenon in Chinese contemporary art. Liang was awarded the Chinese Contemporary Art Award (CCAA) in 2002 and the Prince Claus Award in 2009. In this conversation, he discusses how he has transformed the life process of the silkworm into an artistic language to explore the relationship between human beings and non-human life. He also articulated the association between the Nature Series and philosophy, history and culture, highlighting the integrity of ecology and culture, an idea which has traditionally been highly valued in Chinese culture and art.
\end{abstract}

Yang Jing: Good morning, Mr. Liang. You once mentioned that you first got the idea of using the silkworm as an artistic medium in 1988 when you were working on your installation series $Y i$. In that work, you used dried cocoons. From using dried cocoons to using the silkworm's spinning process, how did the transformation happen?

Liang Shaoji: The series installation Yi was created in 1988. I used the silk and dried cocoon to make the hexagram symbols of the I Ching. One day when this work was put in the exhibition hall of the Zhejiang Academy of Fine Arts, the rain just stopped and the light was shed on the silk tissue, the shadow in the dark space making a hazy and surreal feeling. The dried cocoon and their shadows looked to be overlapping and slighting moving. It reminded me of what Lao Tzu said in Tao Te Ching: Indistinct and shadowy, yet within it is an image; shadowy and indistinct, yet within it is a substance. I was enlightened by such an illustration of the essence of Eastern aesthetics. From that moment, the idea of using living silkworms came to my mind.

Yang Jing: Before the $Y i$, did you even have experience with silk or other natural materials? Had you ever thought of using a living organism for making artworks?

Liang Shaoji: The inspiration I received from the Yi series was a direct reason. But to choose the living silkworm as a medium was never an accidental consequence. It lies in my past experience. When I was studying at the Zhejiang Academy of Fine Arts, I was fond of German expressionism and expressionist art was deeply inspired by primitivism. At that time, the Romanian artist Eugen Popa was teaching in this school. The young students showed great interest in his teaching and the works he made. 
Meanwhile, I liked the works by Shu Chuanxi and Pan Tianshou. The expressionist style in Shu's work and the constructivist characteristics of Pan's work interested me deeply. This school founded by Lin Fengmian has always advocated combining Chinese and Western art. So even though I was trained under the Chistyakov system, the influence I received there made me not totally follow the Russian socialist realist art.

In 1965, after graduating from the middle school attached to the Zhejiang Academy of Fine Arts, when I was planning to apply to the Department of Sculpture, the Cultural Revolution started and the Academy stopped enrolling new students. I had no other choice but to go to work. I was sent to a flax-spinning and weaving factory in Taizhou. It was the largest linen fabrics factory in China, dealing with flax dyeing, spinning, knitting and weaving. This factory produced all kinds of linen products, such as clothes, hats, shoes, curtains, lampshades and carpets, and many of them were exported to other countries. I worked there as a designer, so I had a lot of opportunities to go to beaches, hills and bamboo forests, looking for wild fiber plants, to touch various materials and to cultivate a sensitivity to natural materials. Since the 1960s, in addition to doing my daily job, I insisted on making sculpture and painting, and I never gave up. I also attended provincial and national fine art exhibitions. In the late 1970s, I transferred to the Light Industry Department's Overseas Exhibition Office in Beijing and worker there for more than two years. The experience of working at exhibition planning in large spaces prompted the idea of combining sculpture, painting, architecture and craftsmanship to form a multi-dimensional art. I went to France and Germany in 1982, and then to the USA in 1983. When I went abroad, I visited a lot of art museums and galleries. It was a pleasant surprise for me to find that this possibility does exist as hybridization and indeterminacies are the essential features of the postmodernism. Modern art tapestry can be a way to realize the integration of art forms. So after I returned to China, I began my experiment with three-dimensional fabrics, mixing various skills, such as holing, pulling and stretching, collage and knitting. However, the most important harvest of going abroad was the discovery of the difference between Chinese and Western culture. I realized that the attitude towards nature is the most important division between Eastern and Western cultures; each has been creating its own universe.

In 1986, I got an opportunity to study at the Institute of Art Tapestry Varbanov (IATV) established by Maryn Varbanov at the Zhejiang Academy of Fine Arts. My mentor's love for China and his dedication to his career so deeply impressed me. He set forth the concept of soft sculpture and emphasized the combination of concept, material and space, which cleared up much confusion in my mind and illuminated me the way to transform from folk art into contemporary art. Meanwhile, his concern about nature also deeply encouraged me to shift my view form working indoors to outside. He once planned to cover the West Lake with a net. He was a good friend of Christo Jaracheff, and he even suggested Christo could come to wrap the Great Wall, but unfortunately this plan was never realized. In 1987, Gu Wenda, Shi Hui, Zhu Wei and I had three 
works selected in The 13th International Biennale of Tapestry in Lausanne, Switzerland. That was the first time that Chinese works appeared in the Biennale after the 85' Art Movement. My work was titled The Meaning of Sun Tzu's Book. I mixed bamboo and flax and combined traditional weaving techniques, singeing and writing. Inspired by the chess manual, I put the bamboo slips in many dislocated empty flax-woven boxes. The Art of War was written on the singed bamboo slips. My idea was "to array troops is like weaving". The comparison of hard and soft materials and of real and vague spaces forms a mixture of truth and falsehood which is the essence of the art of war.

In 1989, I was invited by the Artists' Union of the USSR to attend the 3rd International Fiber Art Symposium in Riga, Latvia. During my three-month stay there, I communicated with other artists and had made several works. By the end of the symposium I won first place in the creation contest. But the experience of winning this award triggered my thinking: among over 50 tapestry artists, although some artists had partaken in international exhibitions and made excellent works, many were still restricted in decoration and handicrafts. That made me doubt. For example, if we look at the works of Polish fiber artist Magdalena Abakanowicz, we can feel her deep concern about human destiny. Her works are not merely handicrafts. I thought if we merely focus on decoration, the future development of fiber art would be limited. I started to explore the possibility of the dialogue between fiber art and contemporary art with a firmer determination to strike off the shackles of decoration. In the symposium in Latvia, I made a very interesting work, Fit. This work was formed by three Chinese characters - heaven (天), earth (地) and man (人). Each character was divided into two parts. I made one part in Hangzhou and then the other part in Riga. I included the tickets and vouchers during my residence and other daily items. I wanted to move it back to China and make the two together to express the idea of the dislocation of time and space. But on my train back to China in December in 1989, the political situation in Latvia had an abrupt change. After I returned to China, I made several calls to the Artists' Union of the USSR, but they didn't know how to deal with the situation. Finally, I had to leave it unsettled. I felt a little depressed. But later, I realized that the harmonic fit of heaven, earth and man is a utopian ideal. The humans are always expecting that. This is an endless movement. I felt that this is the essence of art, in an eternal movement without an end point. Later, when people asked me why I chose to use a living animal to make art, I started to recall my experience in Riga in 1989. It made me believe that the value of art lies in the process, not in the result, not in the object finally presented. The possibility of change is more important. Isn't my experiment on silkworm cultivation in which I took the endless life cycle of silkworms a medium for expressing the eternal movement?

Yang Jing: When did you start to raise silk worms?

Liang Shaoji: In January 1989, Yi: Magic Cube, one piece of the Yi series went to the China Avant-Garde Art Exhibition. Then, I started to rear silkworms in the spring of 
1989. The question of life is the starting point of art as well as the ultimate interrogation in art. The scientific miracles created by biology and genetic engineering in the 1980s also greatly motivated me to use art to answer these questions: Where do we come from? Where are we going? What are we doing? For me, silk is a reflection of the trace of time and life on the long journey; it draws an infinite as well as an infinitesimal "one". It is like an unbroken line of life and destiny, and the cocoon is a living body, a universe.

Yang Jing: Did you exchange your idea with domestic and foreign counterparts? What kind of feedback did you receive then?

Liang Shaoji: I first tried to study how to cultivate silkworms at the Zhejiang Agriculture University. The professors warmly showed me around the laboratory and told me that they had never seen anybody making silkworms to spin cocoons on metallic surface. Silkworms would reject metallic materials. When I put the silkworm on the metal frame, it immediately crept away. Then I thought that was very interesting, all possibilities and impossibilities are answers in art. Even the failure would not matter. Realizing this would be a meaningful attempt when China was changing from an agrarian society to an industrial society, my mind was easy. I copied the lecture notes from the university, borrowed sericultural text books and also subscribed to sericultural journals. I left the Zhejiang Academy of Fine Arts and established my studio in Taizhou that is one of the important sericulture bases in Zhejiang. Time flies by and now I have been working in this field for 28 years. My interest in silkworm cultivation was different from that of biologists and silkworm growers. They more focus on how to improve the quality and quantity of silk production. I focused on the life process of the silkworm, associating it with morphology and ecology, and transforming it into a new art form. I consider the history of sericulture in China as a great performance art; our ancestors tamed the wild silkworm and generated a great impact on Chinese culture and aesthetics, as the appreciation of softness, emptiness and quietness. In 1989, when I went to Riga for the 3rd International Fiber Art Symposium, I showed a picture of silkworms spinning on the barbed iron wire to foreign artists. They were very interested to this, but they thought that it would be difficult to define this as fiber art, tapestry or sculpture. I sent the picture of Nature Series No.1 to Hou Hanru. He highly praised my idea. He thought that was unique among Chinese artists. His affirmation gave me great encouragement.

Yang Jing: Yes. You were focused on the aesthetic aspects in the life process of silkworms. You expanded the morphological study to aesthetic thinking; this is something we call art. Of course, silkworm cultivation requires specific technology. What do you think is the most important connection between the two sides?

Liang Shaoji: The connection is experiment. Through the experiment, or we can say trial and error with a playing attitude, I had a new understanding of the biological nature and life process of the silkworm and that made me feel relaxed. The relaxed 
mental status led to the sensitivity, so I could understand the silkworms' pattern of motion, their biological habit and their life miracle. For me, their crawling and spinning, and the influence of the shed, of the smell, light, their biological clock, temperature and humidity on the silkworm all became artistic factors, becoming the starting point of my experiment, and it even became a completed living artwork. Thus my experiment has three meanings: first, it is a way to loosen the bonds of decorative tradition; second, it draws a line between my work and that of silkworm growers; and third, it is a reply to the coming biological century.

Yang Jing: Your works are very experimental. Many critics think it is difficult to categorize them. What do you think of this?

Liang Shaoji: Somebody said that my works belong to installation; I think it is not very accurate. Installation more utilizes readymade objects, mostly daily life objects and existing materials and reorganizes them according to an idea. My material is not at all readymade; it is created from the life process of silkworms. If it is readymade, it is a living readymade work. Take Broken Landscape as an example, I described the lifecycle of silkworms as the 'an infinitely fine line'. Hidden in the silk net are their traces of life: eggs, cocoons, pupae, moths, and the excretions of silkworms. In Chinese, the pronunciations of silkworm (虫), broken (残) and Zen (禅) are very similar. In a sense, a landscape of silkworm is a Zen painting that depicts the contemporary broken landscape. In Listening to the Silkworms, I moved the tools used to cultivate silkworms to the exhibition hall and I invited the visitors to sit in a darkened room and listen to the sound of silkworms living in the adjacent room eating mulberry leaves and spinning cocoons. The remarkable sound is like the bubbling of a running stream or the chirping of autumn insects. When the visitors attend to the sounds of the silkworm's life, they can feel the greatness and mystery of nature and reach a peaceful state of mind. Again listening to the silkworms became listening to Zen.

I spent a great deal of time to study silkworm's spinning on various materials. Xia Yongqing, a well-known professor in sericulture from the Southwest University, once said: "You have researched the silkworm's spinning on metal, broken glass pieces, mirror, stone and the human body so deeply; it is a thesis on silkworm behavior. The ratio of the internal size of the cocoon to the size of the chrysalis is very consistent with our research findings on the ratio of the weight of cocoon to the weight of chrysalis." In order to track the life process of the silkworm, I started to use a video camera and that developed into video art. Meanwhile, performance and dance were also integrated into the Nature Series. In summary, my art is complex; the soul of it is experience and meditation. In 2009, I was awarded the Prince Claus Award, the award statement describing me as "a Chinese conceptual artist who is awarded for his evocative artworks that offer a meditative approach in which art becomes nature and nature becomes art, and for his insightful investigation of the ethics of the human condition and relationship with nature." 
Many conceptual works don't have a fixed from, but I still focus on the form of an artwork. My works have a fixed form and can be preserved for a long time. When I was cultivating silkworms, I thought about ants. The ant kingdom is a very hierarchic and disciplined society, just like human society. I didn't find this kind of hierarchy in the world of silkworms. However, the silkworm's survival on different materials reflects various phenomena in human society. All creatures in the world are seeking for space for living in absurd and unsolvable contradiction. The difficulties of life come not only from the natural world but also the actions of human beings. The broken mirror and the bricks and stone from the debris of the Wenchuan earthquake reflected the survival dilemmas of humans in society. I once wrote: my work is at the point of intersection of art and science, of biology and biosociology. Critic and curator Doris von Drathen once mentioned: "his purpose is not to come up with an aesthetic form that might earn him a new label in the official world of art. Rather, he is concerned with creating something akin to a visual philosophy."

I also pay attention to transgenics, study the pathology of silkworms and optimize their hybridization, and I explore transgenic chromatic silk and the fluorescent silk. But at the same time, I am cautious with the use of technology, always keeping the advice of Heidegger and Hawking in mind. In recent years, there has been a lot of talking about biological art. Biological artworks are mostly made in laboratories. My work is different. I tried to maximally use the factors which exist in the natural process. Based on observation and analysis on the life of the living creature, I find and cultivate its own potential and naturally achieve the transformation. I use biotech in a moderate way to activate genes while avoid violent intervention. In addition, the gene technology is not only a practical approach, but also an aesthetic consideration, as physics without making any metaphysical assumption is meaningless.

In addition, my working process is often accompanied by accidental effects. The biological process of silkworms has often inspired me. My emotion interacts with their biological process; when the situation changes, I follow the change and adjust the concept and method to get to a simple and plain effect. When observing the silkworms spinning, I find that in cold weather the silkworm changes its movement and the shape of silk becomes looser. One day I happened to see silkworms spinning and soon the silk wrapped and covered the metal base of work, and that inspired me to create Snow Cover. So my creation is the use of the natural process and it contains many accidental effects, not only of the accidentals on my side, but also on the side of the silkworms. Without accidentality, there could not be contemporary art. The accidental effects make me meditate, and that can generate new work.

Yang Jing: In my opinion, it's perhaps more appropriate to consider your work as an integrated art. Your work is cross-disciplinary, not only crossing different mediums, but more importantly it connects different disciplines such as art, biology, ecology and sociology. According to your opinion, what is the core concern of the Nature Series? 
Liang Shaoji: My work could last for 28 years because I never thought about into which system I should set my works. I tried all kinds of possibilities. This series is more and more focused on a core value, about nature. I think the division of the Eastern and Western philosophy is the attitude towards nature, which also reflects the different views on anthropocentrism. Through the silkworm, I endeavored to explore nature, to question the time and life; in a simple word, to pursue the Tao through the silkworm.

I spent thirty years understanding the Tao through silkworms. The Tao follows nature; in other words, the Tao is a synonym of the nature. To grasp the Tao, we need not only logical thinking, but also an aesthetic attitude with continuous practice, summarization and reflection. The Tao of Chuang Tzu and Lao Tzu Tao is a kind of chaotic whole thing that is neither the subject nor the object, yet both the subject and the object. To seek the Tao through the silkworm is to observe everything about the life process of silkworms, immerse myself in this process, and then achieve such a status of "I am a silkworm", as if I'm living and metamorphosing with the silkworms. Heidegger mentioned that "devoutness of thinking lies in questioning", silk (丝) became thinking (思) and history (史), and then surpassed individual thinking and history, becoming a poem (诗). Silkworm (槑) becomes Zen (禅).

I once wrote: "silk for me, is the reflection of the trace of time and life on the long journey, it delineates a 'One' which is infinite and infinitesimal." Meanwhile, silk reminds me of salvation. The silvery shining silk emits natural warmth. Silk contains the most important element, amino acids, that make up life. Silk provides positive energy to secure, heal, and revive. Nietzsche once mentioned to look at science from the perspective of the artist, but at art from that of life. Haven't I always been doing this?

Yang Jing: your work interacts with the animal's life course. Your work is process-based, the process of time and life. Can you give any further explanation of the meaning of process?

Liang Shaoji: My work is process-based, so the idea of process means a dynamic body which lies on three levels. First, the silkworm is a living thing, not any industrial material. Second, the making of my work often needs a rather long time; the creation process is the endless life process of silkworms. Third, I put my work under the changing historical and social environments and make them enter a dialogue with different social circumstances. My work enters the flow of time and space and becomes an interactive form.

In addition, in my creative process, I always emphasized experiencing. Western philosophy emphasizes analysis, the Eastern more experience. The dynamic "experiencing" process results in enlightenment, either a sudden or a gradual one. 
The Beds and Chain: The Unbearable Light of Life are the result of life experience and enlightenment. My inspiration for making Beds came from my experience of observing the silkworm spinning. I used to observe the silkworms at night and sometimes I continuously sat up for several nights. One time, after continuously observing them spinning for several days and nights, I was then too tired and fell asleep while I was sitting on the floor. When I woke up after one hour, I found that a silkworm had fallen down on to my shoulder and had already made a thin cocoon on it. I suddenly started to think: am I a silkworm? So I thought of using the burnt enameled wire from the discarded motor to make a number of tiny beds. Then I cultivated silkworms and let them spin on the beds. Year after year, the process went on. This work was made from 1992 to 1999. In 1999, this work went to the Venice Biennale. At that time of the transition of the millennium, people had different interpretations of this work. Some critics interpreted this work as a memory of childhood. A critic from Taiwan considered it as a political metaphor, the confrontation between silk and metal. In this work, the contrast between the feelings of being electrified conveyed by enameled wire and the softness of silvery silk is similar to our living environment at that time, which is filled with a deep anxiety like being electrified. At the beginning, the bed was made too big, because later I found out that the large size destroyed my sympathy to silkworms. Only the tiny size that fits the silkworm can present Chuang Tzu's idea of the equality of things. These swaying tiny beds that staggered and extended in the exhibition hall were weighted by the pressure of the surrounding space while projected a tremendous power, like those matchstick-like figures in Alberto Giacometti's works.

In general, I have been emphasizing the artistic process, contingency and experience. Some critics have thought that I chose to use the silkworm as a symbol of Chinese culture. In fact, this is a misunderstanding. I just employed it as a subject of biological art to re-examine and reveal the essence of human survival from the perspective of contemporary art. The essence is the Tao. I am importing new genes into Chinese silkworm culture. Of course, China's long silk culture and aesthetics provided me with enlightenment and enriched my language.

According to my opinion, some installation artists often make a mistake: they think this is what material A symbolizes and this what B symbolizes and then they put them together and then add their symbolic meanings together. It is wrong to put materials together to get a compound meaning. The encounter of different materials is not $1+1$ $=2$, it is a rather fantastic biochemical reaction. The artist's mission is to discover and activate this miracle, or to create a field where the miracle will occur. The artist uses his wisdom to inspire others to have a new understanding of the world. Because installation artists use ready-made items as material, they must be aware of the issue of over-materialization.

Yang Jing: Yes, materials have symbolic or metaphoric meanings, but art is not science, so the meanings of materials are not fixed and accurate. 
Liang Shaoji: For example, Beuys' use of felt and fat is full of wisdom and sensitivity. His works reflects the spirit of shamanism. The meaning of felt and fat came from his experience of being rescued by Tartar tribe after the airplane crash. His sensitivity to materials was from his life experience. Wassily Kandinski mentioned the spiritual meaning of point, line and shape. I think material is also spiritual. We need to sublimate the material and object into Tao.

Yang Jing: Yes. Your Nature Series found the proper material and a good way to elicit the spirit of the material. You realized a transformation, and in this transformation process you combined natural life and a historical and cultural phenomenon and changed it into art. This process is of course complicated as it refers not only to conceptual transformation, but also to many concrete issues relating to form and technology. This series which started in 1989 is still ongoing. How many works have you made under this series so far?

Liang Shaoji: There is no exact number, but at least more than 250 works. According to my agent, it is difficult to get an accurate number of my works. I often recorded my work and then I did further modification, so the original one in fact didn't exist anymore. Sometimes, I change the building of the same piece according to the different exhibition spaces. Last, I like to put uncompleted or completed work in a new environment to create a dialogue between my work and that environment and then I take photos. For instance, I have been working on this four-cornered pyramid shaped item for many years and it is still going on. If you look from one side, it is like a pyramid; if you turn it upside down, it is a sandglass. I continue to cover it with silk, and take it to meaningful spaces, such as the Museum of Louvre in Paris, the Sagrada Familia Cathedral in Barcelona, the Florence Cathedral and the Forum of Heaven in Beijing. Despite having been photographed, this silk pyramid has never been exhibited, but it will be presented together with photos at the As If solo exhibition in 2018.

Yang Jing: In your 28 years creative process, you experienced certain changes and advances. If you look back the long process, do you think that certain stages can be identified by changes in concept, in the issue focused on, or in the form of the work?

Liang Shaoji: I have not seriously considered this issue. The evolution of the "natural series" can be roughly divided into three stages: the initial stage, the developmental stage and the illusory stage. The first stage was from 1989 to 1999, in which I mainly focused on the conception of the silkworm as a medium, the research into the silkworm's biological habits and the possibility to make a new language with the silkworm. I conducted a lot of experiments in this period. Most works in this period are full of tension and confrontation, showing the cultural conflicts between East and West, the anxiety and the sense of crisis in social transition and the tenacity of the will to survive. The main works from this period include Beds, Self-roped, Nature Series No. 24, Nature Series No.25. Nature Series No. 24 and Nature Series No.25 depicted 
walking on iron scraps on which with silkworms were spinning. In 1999, these works were exhibited at the 48th Venice Biennale, the 4th Istanbul Biennale and the At the New Century exhibition.

The second stage was from 2000 to 2009. On the basis of the first stage, I continued to explore the mediums, forms and materials more deeply. However, the works of this period pay more attention to the whole life process of the silkworm and the internal energy in it. Based on this idea I created a sound installation Listening to the Silkworms that records the sound of the mulberry silkworm spinning and becoming a moth. In Celestial Calendar, electronic program control was added to the nebula map formed by the silkworm to present an instant view of nature, life and the universe. At my 2007 exhibition "Cloud", several pieces, such as Cloud Mirror, Candle, and Mounted were impressive. But the most unforgettable was Chain: The Unbearable Lightness of Being/ Nature Series No. 79. At that time, the stormy social conflicts had gradually faded. A deeper feeling of lightness emerged in my works. When creating Chain, I got my inspiration from watching silkworms dangle down from a roof on their own filaments. It's a moment when life hangs by a single thread, as those little worms climb with great determination along the filament secreted from their own glands, back up the trembling thread. I wrapped the iron chains with silk as if they grew endlessly, implying a sense of the sublime. During this period, I participated in the Lyon Biennale (2000), the Shanghai Biennale (2000) and the Pancevo Biennale (2002), and I held solo exhibitions such as "Cloud" (2007) and "Infinite Fine Line" (2009). In 2009, I was awarded the Prince Claus Award.

The third stage was from 2009. The works in this stage are characterized by vagueness, transparency, insubstantiality and meditation. They also reveal the contemporary dilemmas and express of concern of humanity. The 2014 solo exhibition "Back to Origin", the 2016 solo exhibition "Cloud Above Cloud" and the 2007 solo exhibition "Sha, Sha, Sha" all reflect the pursuit of this period. Chuang Tzu's "to the extreme of emptiness" inspired me; as it is an Eastern perception of minimalist art. Planar Tunnel reveals the infinity of the time and space of life, universe and history through the filmy and mysterious silk pieces woven by silkworms. When the silkworm begins spinning a cocoon, it moves its head in a figure-eight-shaped pattern. In Mending Sky, I took videos of the figure-eight-shaped movement pattern which resembles very much a string of stitches on clothes and used the broken mirrors to reflect it. Stele depicted the cluster of silkworms crawling and wriggling, casting a shadow on screen and forming an amazing piece of calligraphy - like a stele of the Chinese ancient silkworm script. In A Move in Silence, the light and shadow of the cloud like silk spread on the acrylic sheets, making an effect of the coexistence of quietness and motion. Destiny and The Origin of Cloud - Wenchuan Stones are the continuation of the humanitarian concern. Destiny, an enormous mixed-media installation, uncovers a chapter of shocking scenes: the giant metal chains wrapped and covered by silvery and soft silk crawling out of a broken and rusty black box, squirming painfully back into mud. It is an allegory of natural catastrophes and 
man-made calamities such as traffic accidents, oil pollution and war. It is the allegory of destiny. In this period, I mainly attended the "Art of Change" exhibition at the Hayward Gallery in London and another exhibition, "What About the Art? Contemporary Art from China", at the Qatar Museums Gallery Al Riwaq in Doha.

Yang Jing: The concern in your work is rather wide, not only on the relationship between humans and nature. For example, your work Moon Garden is a review of ancient Mesopotamian civilization and the complicated political and cultural conflicts in that region today.

Liang Shaoji: Yes. In 2016, Moon Garden was first displayed at the Qatar Museums. In addition, I have also made two other works since last year, titled Aegean Sea and In Silence, respectively. In Aegean Sea, the winged Victory that had been at the prow of the boat has disappeared, the boat's wreckage has become entwined by silk, and there is a white veil over the bow. On the ground are several pieces of feather and the goddess is gone. This work is a reflection on the refugee crisis in Greece. In the work In Silence, a pile of empty plastic tank were scattered in the corner, implying the 2015 Tianjin explosions. The three works refer to three ancient cultures: Chinese, Greek and Mesopotamian. The dilemmas they are facing today are presented through the silk.

Yang Jing: The meaning of an art work is often multivocal and ambiguous. The association of an art work with ecology, politics and society is not as clear as the concept expressed by language.

Liang Shaoji: Deleuze distinguishes art, philosophy, and science as three disciplines, each analyzing reality in different ways. He thought that philosophy creates concepts; science creates quantitative theories, while art creates innovative expression by combining sensation and feeling. So an artistic perception cannot be totally correspondent with philosophical concept and a scientific theory.

Yang Jing: As for the philosophers, who has had bigger impact on you?

Liang Shaoji: I have had a cursory read of works by Eastern and Western philosophers. In traditional Chinese works, I like Lao Tzu and Chuang Tzu's philosophy. In Western works, I read more about the works of German and French philosophers. I am fond of Chuang Tzu because of his rich thinking about life and aesthetics. Among Western philosophers, I was fond of Nietzsche in the 1980s. With the passage of time and advancing years, I read Heidegger more. In addition, I also read Deleuze, Foucault, Benjamin and Agamben. Heidegger's thinking has had a deep influence on me. His idea about the technology is inspiring to us today. Heidegger regarded poetry as measure-taking and the obligation of a poet is to return as a native, but I prefer, in this case, to change "poetry" into "silk" (the two words poetry (诗) and silk (丝) are homophones in Chinese), and thus "silk is measure-taking 
and the obligation of silk is to return as a native". I am currently living in the Tiantai Mountain. It is home to the Tiantai sect of Buddhism. The Tiantai Mountain is always wreathed in mist. The clouds are a vital force, like the breath of nature. After I returned to Tiantai, I made a lot of works dealing explicitly with the clouds. I made Cloud Mirror, the surface of the mirror entwined with silk, and I install the mirrors on a platform where the founder of the sect, Zhiyi, is believed to have meditated and faced the mirrors towards the blue sky. The drifting clouds in the blue sky were reflected on the mirror, the reflection of the real clouds and the cloudy silk on mirror face were mingled into an integrity, which generated a phantom. I was mediating beside the mirrors. Somebody talked about the association between my work and Heidegger's returning Home. I don't think it is simply returning to the natural environment; my returning to Tiantai Mountain was a kind of spiritual returning Home.

Yang Jing: Heidegger's concept of the Fourfold - the Heaven, the Earth, the God and the Mortals questioned the position of human beings in the world. It is a deep reflection on the viewpoint of the human being as being the king of all species and the conqueror of nature. His philosophy is inherently connected to the Chinese ancient philosophy of Lao Tzu and Chuang Tzu. His idea constitutes a critique of the anthropocentric worldview since the Enlightenment. But do you think Heidegger's idea of the poetic dwelling on earth can be realized in our society today?

Liang Shaoji: According to Heidegger, dwelling is the manner in which mortals exist on earth. He also pointed out that "the real plight of dwelling is indeed older than the world wars with their destruction, older also than the increase of the earth's population and the condition of the industrial workers. The real dwelling plight lies in this, that mortals ever search anew for the nature of dwelling, and that they must always learn to dwell." This is similar to what Lao Tzu said that "this returning to the root is called quietness; it is the fulfillment of one's destiny."

I think the realization of human's poetic dwelling on earth is unreachable. But if we have such an ideal, human society will at least have an ultimate goal to strive towards. This is what we mentioned earlier, Utopia is unreachable just like our pursuit for the truth. This is something that philosophy and science can't clarify; the artists can express their ideas and inspire the people. This is the life of art lies. We talked about time and life. It is an ecological issue and an eternal concern. Ecology includes many issues, including cultural and social dimensions. Sometimes artists express their concern about human destiny as a whole instead of focusing mainly on a specific ecological and environmental issue.

Yang Jing: The study of ecological art should avoid an oversimplified interpretation of the artist's work and avoid merely using an ethical criticism to replace an artistic criticism. After a long time you conquered a technical difficulty, which is, the silkworm's rejection of metal, and successfully made the silkworm spin on a metal 
surface. Later, you successfully made the silkworm spin on plastic, glass and many other artificial materials. Can you say something about how you managed to do this?

Liang Shaoji: First of all, why did we think that it is impossible to make silkworm spinning on metal? Previous researchers and silkworm growers didn't study this issue because it was of no concern to them. When I asked them, they told me that because silkworms eat leaves, they feel comfortable with materials containing lignin. For example, paper contains lignin, so the silkworm can get along with paper. Metal is cold and doesn't contain lignin but has a metallic taste. I used to use metallic waste which often had greasy dirt on it. The silkworm is very clean, so naturally they won't like metallic surface. But this is precisely the starting point for my philosophical and aesthetic thinking, to interrogate the circumstances in which life can survive and live. Domestic silkworms evolved from wild silkworms. The wild silkworms have stronger immunity; the domestic silkworms have lower immunity but they have very advanced silk gland, which is the result of human domestication. To make the silkworm able to adapt to different material, first we need to improve their immunity. To improve their immunity and adaptability, I had to optimize the breed through selective breeding and interbreeding. Second, the silkworm's spinning is controlled by its biological clock. Once I have mastered its biological clock, I can control the silkworm's spinning speed, direction and shape through adjusting the temperature, humidity, smell and light in the shed. It was a complicated and tortuous course to master all these things in practice. It was very difficult to make the silkworms spin on a human body. Humans sweat and the silkworms don't like sweat. The human body has certain slight smell, and the silkworm doesn't like that either. Also, humans can't stop moving for a long time, but the silkworms can spin only in a still and silent situation. When the density of silkworms is high, their smell overwhelms the smell of the human body. It then becomes possible for them to spin. But if the density is too high, the silkworm can't spin. So it needs practices and adjustments. I have made a rough calculation, and in the past years I have reared at least 900,000 silkworms, and if each healthy silkworm produces 1000 to 1200 meters of silk, the silk I used would go round the earth more than 10 times.

Yang Jing: Your works have fascinating shapes. How have you been able to design and develop shapes on different surfaces?

Liang Shaoji: At the beginning, I generally have a rough idea and make several sketches. When the silkworm starts to spin, I observe, wait and sometimes make certain adjustments along its natural course, similar to making a splash ink painting. Many works were made in several times; the piling of silk can't be completed in one time. It is my pleasure to discover miracles, so I am actually wandering between being a silkworm farmer, a researcher, an artist and a stylite. The control of the shape varies from work to work; in some works I had more control and made more adjustments while in others I had less control. For example, when making Broken Landscape, I had almost no control on the shape. In Listening to the Silkworms I made a natural 
time and space for meditation. When I was planning the exhibition in Kosovo, according to the plan the silkworms were supposed to change into moths at the beginning of the exhibition. So I had to calculate and know when I should start to raise the silkworms. This is to master the rule of the life process of the silkworm. Different from many biologic arts, I make maximal use of the natural status of life, and discover the possibilities from this natural process. This is to distill the artistic form from the natural form.

Yang Jing: Right, this is different from most biological art works which are made in a laboratory. Both the concept and process are different. I have found that Chinese artists' practice of the use of living animals to make art have mostly not been successful. Many works raised ethical arguments. For example, in the 1990s, for Yu Ji's Kiss of Special Creature, the artist sat in a huge glass box surrounded by 1000 chicks. He kept putting chicks in his mouth to kiss them. That caused the death of some chicks. In Dai Guangyu's work, Revival, 96 Chengdu, he prepared 10 plastic bags filled with water and put two fish into each bag. The plastic was then sealed. When the oxygen was gradually depleted, all fish died after several hours. These practices gave rise to arguments and as a result almost all Chinese artists have given up those ways of using living animals to make art.

Liang Shaoji: Yes, among Chinese artists, I am not the only one who uses the living animal in art. Huang Yongping has also done so. He once used locusts. In his Theater of the World, he put scorpions, spiders and grasshoppers in a transparent box, and let them kill each other. In addition, the artist Lu Yang used the dead body of frogs dissected at a medical university, and connected them to electronic codes. After plugging in, the legs of dead frogs started to move according to the powerful electronic beats, looking like dancing a ballet in water.

Yang Jing: Theater of the World is a metaphor for human society. This shows that people from different nations and cultures cannot get along with each other in peace; instead, human beings are devouring each other. But in my opinion, these works show that human beings manipulate the life of other animal species. In a sense, it is the presentation of anthropocentrism. This is not a rare case in contemporary art; a lot of works which are intended to move away from the anthropocentric view are still anthropocentric in the sense of the production process and presentation.

Liang Shaoji: Many works are intrusive, in that humans are controlling the animal's life. Heidegger criticized the human domination and conquest of nature for human ends. Chuang Tzu's On the Equality of Things represents respect and awe for nature, and the harmonious integration of the two. Our art making should follow the rule of nature. The Tao in silkworms has guided me. I have had a dialogue with silkworms. I have taken the life process of the silkworm as a subject for observation and meditation. I tried to make maximum use of the factors which exist in the natural process and can be changed into art and to avoid excessive intervention. 
I remember some foreign artists used bees in art making, and some used spiders. But silkworms have connotations with an Eastern aesthetic. I had a work Candle, which was inspired by an ancient poem: Till the end of life a silkworm keeps spinning silk, and until it burns itself out a candle goes on lighting us. The silkworm is an insect which undergoes complete metamorphosis. It is different from the spider. The spider's metamorphosis is incomplete, in that its larva phase does not looks so very different from the adult. I'm stilling working on this series and exploring all kind of possibilities. But I understand that more I work on this, the more challenging it will become. But now l'm still observing and meditating and the lives of these small animals are still giving me endless inspirations. For example, I recently was focused on the association of silk and light. In fact, in the dim and illusionary shadow of dried cocoons in the late 1980s, in the mirrored image of Mending Sky created after 2010, in the Stele inspired by creeping silkworm script, or in the light halo in Silence and Moon Garden, there has been the language of light. The speed of light and the wormhole that the scientists Einstein and Hawking described in astrophysics, the words of the philosopher Agamben that the darkness is a kind of light, the light that is coming towards us but has not yet arrived, have all enhanced my meditation. Silk is the apostle of light, a laser instrument of life, and is a mysterious wave that summons redemption and traverses every phenomenon. I think that the "As If" exhibition not only expresses speed and space, the illusory image and historical memory. It is also a reflection of contemporary predicaments and the pursuit for another world and for a rebirth. This pursuit will be sublimated into a mass of light. This is the concept of the upcoming "As If" exhibition: after thirty years' pursuit of the Tao through the medium of silkworms, the Tao is there.

\footnotetext{
i This interview with Liang Shaoji was conducted at the artist's studio at the Tiantai Museum in Zhejiang on 7 August, 2017. The interview was originally in Chinese and translated into English by the author. The Chinese transcript was reviewed and approved by artist Liang Shaoji and kept in the possession of the author.

ii Yang Jing is an art researcher from China. She is currently undertaking a post-doctoral research at the Department of Music, Art and Culture Studies of the University of Jyväskylä, focusing on ecological awareness in Chinese contemporary art. Yang's research on ecological awareness in Chinese contemporary art is currently granted by the Finnish Cultural Foundation.
} 